\title{
5th generation district heating and cooling systems as a solution for renewable urban thermal energy supply
}

\author{
Stef Boesten $^{1}$, Wilfried Ivens ${ }^{1}$, Stefan C. Dekker ${ }^{1,2}$, and Herman Eijdems ${ }^{3}$ \\ ${ }^{1}$ Department of Science, Open Universiteit, Heerlen, the Netherlands \\ ${ }^{2}$ Copernicus Institute of Sustainable Development, Utrecht University, Utrecht, the Netherlands \\ ${ }^{3}$ Mijnwater B.V., Heerlen, the Netherlands
}

Correspondence: Stef Boesten (stef.boesten@ou.nl)

Received: 29 May 2019 - Revised: 22 August 2019 - Accepted: 5 September 2019 - Published: 20 September 2019

\begin{abstract}
In order to reduce greenhouse gas emissions and decrease dependency on depleting fossil fuel resources the shift to a renewable energy system is necessary. District heating and cooling systems are a viable solution to provide heat and cold in urban environments. Renewable heat and cold sources that may get incorporated in future urban energy systems will not provide the same high temperature output as current fossil fuel fired systems. Fifth generation district heating and cooling (5GDHC) systems are decentralized, bidirectional, close to ground temperature networks that use direct exchange of warm and cold return flows and thermal storage to balance thermal demand as much as possible. 5GDHC offers a way to incorporate low temperature renewable heat sources including shallow geothermal energy, as well as reduce total demand by recuperating generated heat from cooling and generated cold from heating. The large scale of 5GDHC allows for optimal design of technical parts like heat pumps and thermal storage vessels, while increasing overall system efficiency by incorporating a large variety of supply and demand profiles. We provide a definition for 5GDHC and show how this concept differs from conventional district heating systems. The Mijnwater system in Heerlen, the Netherlands is showing what a city-level 5 GDHC system can look like.
\end{abstract}

\section{Introduction}

In order to keep the effects of climate change limited, the United Nations (UN) have agreed to keep the average global temperature increase below $2{ }^{\circ} \mathrm{C}$, compared to pre-industrial levels (UNFCCC, 2018), while pursuing efforts to keep the temperature increase below $1.5^{\circ} \mathrm{C}$. To do so, greenhouse gas emissions will need to be reduced by $95 \%$ in 2050, compared to 2010 (IPCC, 2018). In the European Union, buildings consume $50 \%$ of the total energy demand, emitting $26 \%$ of $\mathrm{CO}_{2}$ emissions (European Commission, 2018). Most of these buildings can be found in cities, towns and suburbs, as $72.5 \%$ of EU inhabitants live in urban areas (EuroStat, 2016). This means that in order to reach the UN climate goals, a transition towards a fossil-free urban energy system is needed.

In the Netherlands the transition to the future urban energy system is directly linked to the national government's decision to stop using domestic natural gas from the province of Groningen. To address earthquake related safety concerns, the Dutch government aims to completely stop natural gas production in this field by 2030 (Wiebes, 2018). Currently, over $90 \%$ of Dutch residences use natural gas for space heating, cooking and domestic hot water, consuming $289 \mathrm{PJ}$ in 2015 (ECN, 2017). Service related buildings like offices, schools and hospitals consume another $127 \mathrm{PJ}$ of natural gas (ECN, 2017). Together, this amounted to more than $30 \%$ of natural gas consumption from the Groningen field in 2016 (ECN, 2017). This cannot be substituted easily with natural gas from other fields, because of its specific caloric value. Using imported natural gas not only has geopolitical implications, it also requires expensive facilities to add nitrogen. An upgrade of the existing mixing facility is planned to be completed by 2022 , but the total capacity will not be enough to completely cover demand (Wiebes, 2018; ECN, 2017). This results in a double incentive to shift to a new energy system in the Netherlands, one that is both low in greenhouse gas emissions and does not use natural gas from Groningen. 
An alternative way of providing heat in urban environments is the use of district heating systems. These supply hot water or steam to consumers using a network of pipes. District heating networks can be local to a group of buildings or single neighborhoods, or span entire cities. Heat is usually produced in a central facility, which is often a fossil fuel fired combined heat and power (CHP) plant (Werner, 2017). Even though this is a highly efficient process, it is not based on renewable sources and therefore not a sustainable alternative to using natural gas.

Most of the heating requirement in the urban environment in Europe is low temperature (Sanner et al., 2011). Connolly et al. (2014) show that low temperature district heating systems can potentially supply five times as much heat in 2050 as conventional district heating systems. This way, low temperature sources like geothermal, surface water and sewage water can supply around one third of the European heat demand, making its thermal potential larger than from sources like biomass incineration or waste-to-energy heat production (Persson, 2015). Also in the Netherlands low temperature geothermal energy is showing the single largest potential of providing renewable heat (Hoogervorst, 2017). At the same time the potential for renewable high temperature sources like biogas and solid biomass is limited (Hoogervorst, 2017), making them unsuitable for large scale application in urban energy systems. A resilient urban energy system should facilitate the utilization of renewable, local, low temperature sources.

In the Netherlands less than $4 \%$ of heat demand in the built environment is supplied by district heating systems in 2017 (ECN, 2017). However, district heating is considered a viable solution for urban areas to replace natural gas infrastructure for heating by 2050 (Sanner et al., 2011; CE Delft, 2016; Planbureau voor de Leefomgeving, 2017). In order to make this new heating regime ready to operate fully on renewable sources, it needs to be designed differently than current conventional district heating systems (Lund et al., 2014). One alternative district heating and cooling (DHC) system that is proposed, is called fifth generation district heating and cooling (5GDHC) (Buffa et al., 2019; Bünning et al., 2018). These 5GDHC systems work with near-ground temperatures and allow for bi-directional exchange of heat and cold between connected buildings, facilitated by seasonal storage. This way the total energy demand in a district can be greatly reduced, while renewable sources like solar thermal or geothermal can be incorporated to cover the residual demand.

This paper presents the 5GDHC concept as an advanced and sustainable urban energy system. Section 2 introduces 5 GDHC and shows how it combines concepts from conventional DHC and local energy projects to come up with an integrated urban energy solution. Section 3 shows how the Mijnwater system in Heerlen, the Netherlands applies 5GDHC in practice. Section 4 discusses the context of 5GDHC and suggests future work to be done on this topic.

\section{Fifth generation district heating and cooling systems}

District heating systems can be found in cities across Europe, North America and parts of Asia. Lund et al. (2014) provided an excellent overview of the development of district heating systems over the past century and a half. The earliest generations of district heating systems used pressurized steam. Later systems used pressurized water and from the 1970s onward the Scandinavian model with working temperatures around $90^{\circ} \mathrm{C}$ became standard. The decreasing temperature and increased standardization of components allowed for lower transportation losses and increasing variety of heat sources, like residual heat from waste incineration and geothermal heat sources.

According to Lund et al. (2014), future generations of district heating systems should be based on renewable energy and facilitate substantial reductions in heat demand. They defined some properties that future, or fourth, generations district heating systems should have in order to fulfill its role in sustainable energy systems, which are:

1. the ability to supply low temperature heat to both existing, renovated, and new buildings;

2. having low grid losses;

3. the ability to recycle heat and integrate renewable sources;

4. the ability to be an integrated part of a renewable multienergy system (MES), including cooling;

5. having a sound business model, also in the transition to renewable energy sources.

Connecting local clusters of buildings to collectively benefit from a renewable source of heat is relatively common practice. The buildings on the campus of the Swiss Federal Institute of Technology in Zürich are connected to a group of borehole thermal energy storage systems via a local grid, by which they manage to cover over $90 \%$ of their total heating demand (ETH Zürich, 2017). The Drake Landing Solar community in Canada is a group of 52 detached homes that managed to reach a $97 \%$ solar fraction on their heat demand using a collective storage system for their solar thermal collectors (Mesquita et al., 2017). There are numerous examples of systems like this, such as cold district heating networks (CDH) (Pellegrini and Bianchini, 2018) and bidirectional low temperature district heating (LTDH) (Bünning et al., 2018). Although they greatly improve the climate performance of the specific site, the solutions are not designed to be scaled up to city level sizes, possibly missing out on economics of scale advantages (Truong and Gustavsson, 2014). Fifth generation district heating and cooling (5GDHC) combines the properties of local renewable energy systems with the principles of future district heating as defined by Lund et al. (2014). 


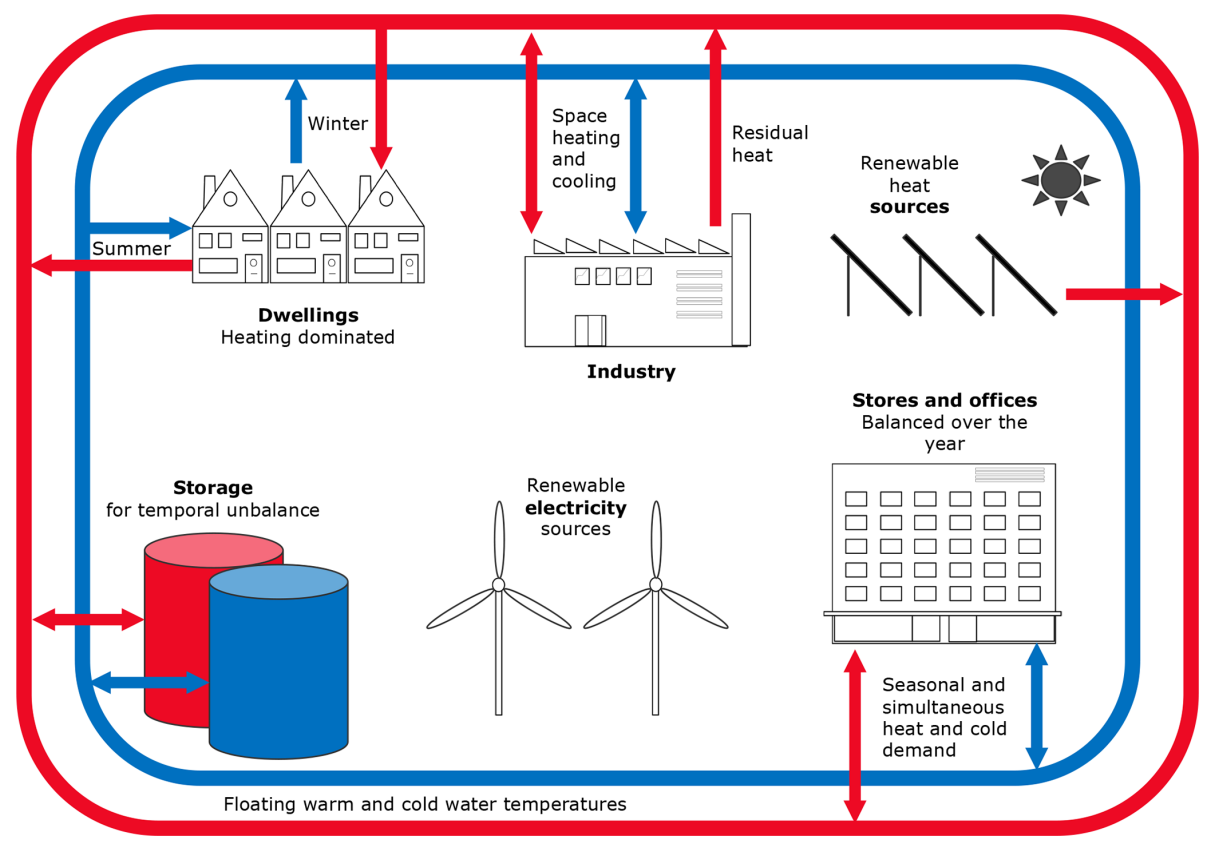

Figure 1. A circular representation of a 5GDHC system. The network is balanced over the year, with warm return flows from cooling supply and cold return flows from heating supply covering as much of the demand as possible. Any residual heat or cold demand is supplied using renewable sources.

Conventional district heating systems have a linear design. Heat is generated at a source and transported to the consumers using hot water. There is a return flow of water, which has no value from an energy perspective. A 5GDHC system is non-linear, bi-directional, and decentralized. In principle, each consumer can operate as a producer (Buffa et al., 2019). Ideally, heat and cold demand should be of similar size (Bünning et al., 2018), in which case the system can be almost circular.

Analogue to electricity micro grids, bi-directional decentralized district heating and cooling grids have the potential of turning each connection into a "prosumer". 5GDHC does not have return flows as such, but warm and a cold pipes (Bünning et al., 2018). Heat pumps at the building site are connected to both cold and warm water lines. In case of heat demand, the building withdraws water from the warm line, uses it in a heat pump to reach the required heating temperature and discharges to the cold line. When there is cooling demand, the system works in the opposite direction, charging from the cold pipe and discharging warm water to the warm pipe.

The principles of non-linear and bi-directional flow and lack of return flow are not new in local heating systems. It is new to scale these principles up to the scale of a city, with a multitude of demand types and sources of heat and cold. Figure 1 shows a schematic overview of a 5GDHC system at the district level. This representation emphasizes the closed nature of 5GDHC. Different types of consumers - residents, industry, offices - offer different types of load profiles. Some of these are balanced over the year, others are heat or cold dominated. The role of the warm and cold grid is not to linearly transport heat or cold from a supplier to a consumer, but rather to facilitate in exchanging residual heat or cold between connected buildings. Storage facilities act as buffers to bridge the temporal gaps between demand and supply. Renewable electricity sources are integrated by running transport pumps and heat pumps at times of high availability of renewable electricity. During times of lower availability of renewable electricity thermal energy supply can rely on (local) buffers and building thermal mass. Sources with a large thermal radius, like shallow geothermal energy, can be spread across the city, making optimal use of the available heat and cold.

The temperature in both the warm and the cold pipes are free-floating. Usually, the temperatures are close to ground temperature and therefore not suitable for direct heating purposes (Buffa et al., 2019). By allowing free-floating temperature, an increase in the warm pipe is allowed if this is beneficial to accommodating higher temperature sources. This way, grid temperatures can be optimized for maximum overall system performance. As in electricity grids, the thermal grids can then operate as a virtual storage for the prosumer (Bünning et al., 2018).

The use of both short-term and seasonal energy storage is a key part of a 5GDHC system. It allows for bridging the temporal gap between supply and demand of heat and cold, as well as temporal gaps between availability of renewable electricity and operating moments for heat pumps. Thermal 
energy storage can also significantly reduce the required heat pump power output, which has a major impact on the investment costs. There is definite potential to exchange heat in a situation of simultaneous heat and cold demand in neighboring buildings (Walker et al., 2017). This benefit increases with the scale of the system, as more variety of load profiles increases the likelihood of simultaneous demand and supply, which can cancel each other out. Most heat demand will still occur in winter while most cold demand occurs in summer. Seasonal storage allows for the heat surpluses in summer to be used to cover part of the heat demand in winter.

Cooling demand is expected to grow significantly in the next few decades (Sanner et al., 2011), especially in cities, where urban heat island effect leads to faster temperature increase than in rural areas (Kolokotroni et al., 2012). With the absolute cooling demand in the EU being about a sixth of the absolute heating demand in 2050 (Sanner et al., 2011), a large part of the heating load in urban areas can be covered using recuperated cooling return flow. The residual demand should be covered using renewable heat sources like deep or shallow geothermal, surface water or sewage water, solar thermal, or any other source that happens to be locally available. A larger 5GDHC system can facilitate multiple types of heat and cold sources and since the system is intrinsically modular, new sources can be added as the system expands.

5 GDHC systems will have a considerable number of degrees of freedom. This is reflected in Fig. 2, in which the temperature levels and heat pumps for an individual connection are represented. Operation of a 5GDHC will need to take into account, among other things, grid temperatures, supply and return temperatures of the building heat pumps, storage sizes and temperatures, and source temperatures and timing of operation. In Fig. 2 each temperature level has its own dedicated heat pumps and buffers, with an optional heat pump for domestic hot water production in case the regular heat pump is not able to reach sufficiently high temperatures. These characteristics, together with the integration of renewable electricity sources, makes 5GDHC effectively a multienergy system (MES).

\section{5GDHC in practice}

The Mijnwater DHC system in Heerlen, Netherlands is technologically one of the most advanced 5GDHC systems (Buffa et al., 2019). Originally a local district heating and cooling network using a flooded coal mine as a low-temperature geothermal source, it has been transformed into an urban smart DHC grid, incorporating several decentralized heat sources (Verhoeven et al., 2014; CE Delft, 2018). This includes a data center, residual heat from supermarket refrigerators and from small scale industrial processes, as well as the warm return flow from space cooling in the connected buildings. Currently Mijnwater services over $200000 \mathrm{~m}^{2}$ of building floor area. A large role has been given

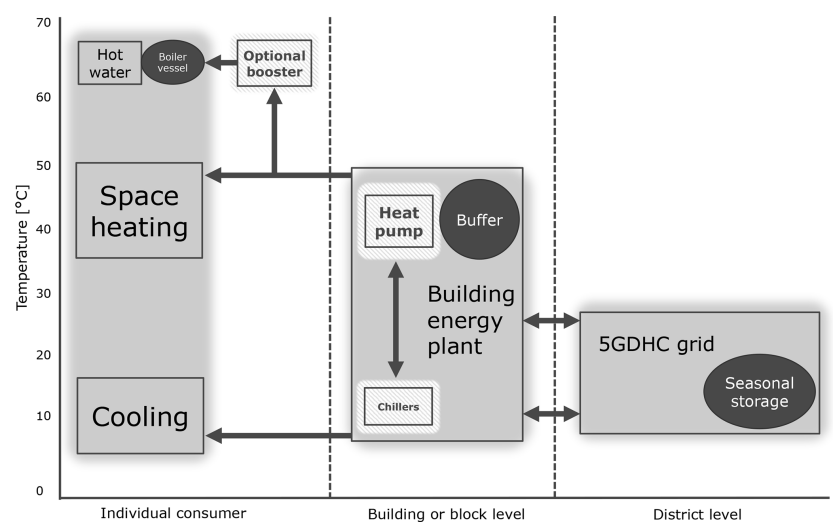

Figure 2. Overview of an individual connection in 5GDHC. Several temperature levels can be distinguished, with the temperature only getting upgraded as close to the demand side as possible.

to Mijnwater in the regional energy strategy to transition the region with 250000 inhabitants to a carbon-neutral energy system in 2040 (PALET 3.0, 2016). The development of Mijnwater reflects the principles of 5GDHC, as it is developing from a local project engineered for an individual heat source to a modular urban-scale grid.

Figure 3 gives an impression of the Mijnwater system, with several clusters connected to a backbone system. This backbone was initially intended to connect consumers to the flooded coal mine that acted as a geothermal source. Now, it is supporting bi-directional flow of warm and cold water, connecting the clusters to each other as well as to the mines. A cluster is connected to the backbone via heat exchangers placed on a skid in a concrete underground "cluster basement" (Verhoeven et al., 2014). The flooded mine is now used as seasonal thermal energy storage system with an enormous capacity. By balancing the clusters internally in terms of supply and demand, the system facilitates modular expansion as each cluster will put only a limited capacity demand on the backbone and the centralized storage system.

All connections to the Mijnwater grid are bi-directional and are able to deliver both heat and cold throughout the year (Verhoeven et al., 2014). This is reflected in the twopipe structures of the backbone and cluster grids. Originally, Mijnwater was designed and built as a three-pipe grid with a warm and a cold supply pipe and a common return pipe. In coherence with 5GDHC principles, the return flow pipe is no longer in use, and the cold and warm lines are now bidirectional.

Buildings are connected to the cluster grids via building energy plants. The step-up heat pumps and chillers are located there. "Step-up heat pump" is the name given to the low temperature heat pump, as not to confuse it with the hightemperature booster heat pump used to supply domestic hot water. A building-level buffer of typically $1000-3000 \mathrm{~L}$ can be used to supply water at space heating temperatures during moments of peak demand. 


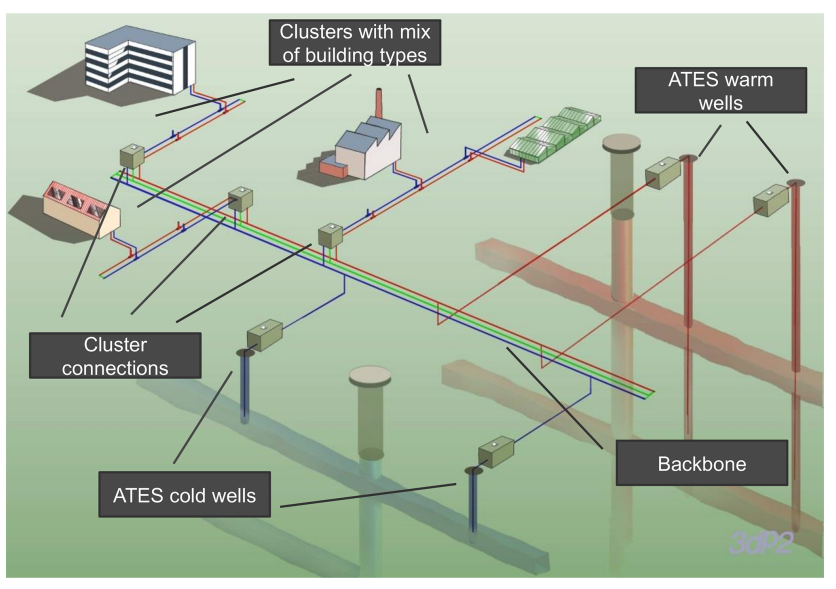

Figure 3. An artist's impression of the Mijnwater system. The figure shows three cluster connections, the backbone pipes, and the warm and cool wells. (courtesy Mijnwater B.V.).

A step-up heat pump upgrades heat flows from cluster temperature level to space heating temperature level, which is dependent on the outdoor weather. It supplies the required temperature for space heating, which can also be used as input temperature for the booster heat pump. A cooling heat pump provides space cooling using the cold cluster level and adds the recovered heat to the warm cluster. Both these heat pumps can operate on each others return flows, providing opportunity to locally resolve both heating and cooling from simultaneous demands.

For domestic hot water there is a booster heat pump and water storage vessel of $120-200 \mathrm{~L}$ as close to the point of demand as possible in order to minimize transportation losses. By making smart use of this storage vessel, the capacity of the booster heat pump is quite limited at $500 \mathrm{~W}$ electric. Dutch households have an average demand profile of $20 \mathrm{~min}$ of hot water consumption per day. The booster heat pump can take the full $24 \mathrm{~h}$ to generate this amount of heat, when necessary, because of the large storage capacity. If a building has only one user, like a single-family home, the booster heat pump is placed in the energy plant. In buildings with multiple users, like shared office buildings or apartment blocks, each user has their own booster and water vessel.

\section{Discussion}

A wide range of renewable sources can serve as alternative to fossil-based heat (Winkel et al., 2013). Sanner et al. (2011) show that shallow geothermal sources are omnipresent in Europe and that they can potentially cover a quarter of total heating demand in Europe, with deeper geothermal having the potential of covering another quarter of the demand. Solar thermal has about the same potential as shallow and deep geothermal combined (Sanner et al., 2011; Connolly et al., 2014). This introduces more variability in temperature and timing of supply than in current Scandinavian model district heating systems (Lund et al., 2014). At the same time enhancing building thermal insulation reduces both the total heat demand and the required temperature for heating buildings, while generating a substantial cooling demand. As large scale systems benefit from economies of scale (Truong and Gustavsson, 2014), it is advantageous to design large scale systems that are flexible enough to account for differences between buildings in space and time and to accommodate a wide variety of renewable heat sources. Fifth generation district heating and cooling is a proposed resilient urban energy infrastructure design that can supply heating and cold at required temperatures to consumers, reducing total energy demand by facilitating direct heat exchange and uses renewable sources to cover residual demand.

The variety of temperature levels and the integration of electricity infrastructure make 5GDHC a multi-energy system (MES). Optimizing design and operation of such a system is a non-trivial process. We propose to use the energy hub concept, which analyzes MES from an input-output perspective (Mancarella, 2014). Mohammadi et al. (2017) define an energy hub as "a multi-generation system in which production, transmission, storage, and consumption of multi-energy carriers take place to meet different type of demands". In principle all types of fuels, electricity, as well as other types of energy carriers can be inputs or outputs of an energy hub (Geidl and Andersson, 2007). Geidl and Andersson (2007) showed that the energy hub concept can be applied to a wide variety of technologies, optimizing combinations of storage and conversion for both costs and emissions. This makes it an effective tool to capture the complexity of 5GDHC systems. The review by Mohammadi et al. (2017) shows that energy hub literature mostly covers natural gas and electricity networks. Mohammadi et al. (2017) notice that such a focus on natural gas based infrastructure and technologies reduces the potential of these models to present $100 \%$ renewable energy systems. While district heating and cooling systems have been integrated in energy hubs before, these models worked with a linear representation of supplying district heating and cooling from a centralized source (Orehounig et al., 2014). As energy hub carrier flows are usually expressed in terms of energy, temperatures of the warm and cold water flows were taken implicitly. In terms of input-output, this means that there is a direct one-to-one conversion of a unit of district heat input to a unit of heat demand. Since 5GDHC does not have return flows, heat pumps will deliver a unit of cold to the potential supply side for each unit of heat that is delivered to the demand side. To allow for these floating temperature levels, some additions to existing energy hub concepts will need to be made.

Districts or regions are almost always considered from an administrative point of view. The concept of the Dutch Climate Agreement (Nijpels, 2018) proposes a neighborhood approach based on administrative neighborhoods as a means to conduct the energy transition. However, from an energy 
efficiency perspective this is likely not the optimal unit of assessment, as it leads to highly uniform neighborhoods which likely have highly similar energy demand and supply patterns. In finding an optimal design of a 5GDHC cluster, the boundaries of the neighborhood should ideally not be set beforehand. Rather, the optimal solution might be not to include all buildings in the district, or to include some buildings from adjacent neighborhoods. Energy infrastructure follows urbanization, but it also has the capacity to structure urbanization patterns (Juwet and Ryckewaert, 2018). In new developments, structures' energy profiles may have be taken into account in urban planning, creating neighborhoods with complementary demand profiles. Experiences with the Mijnwater system have shown that, given matching demand profiles, a 5GDHC system can be set up in developments starting at approximately $75000 \mathrm{~m}^{2}$.

Mijnwater is among the technologically most advanced 5GDHC systems (Buffa et al., 2019). Based on the principles tested in Heerlen, five pilot projects for 5GDHC are being developed as part of the Interreg NWE project "D2Grids" (D2Grids, 2019). These projects are situated in Bochum (Germany), Brunssum (Netherlands), Paris (France), Glasgow, and Nottingham (United Kingdom). This project aims to provide industrial standards for 5GDHC in order to enhance the modularity of its design.

Mijnwater has already shown that 5GDHC is a proven system, both in new and existing buildings (Verhoeven et al., 2014). In the development of the system there has been some leeway for trial-and-error, as the flooded mines have an enormous storage capacity and can act as a geothermal source when necessary. Implementing a cluster without the mine reservoirs for the first time requires a good analysis method to size the variety of the required technologies. Mijnwater is decreasingly using the mines as geothermal source, while increasingly relying on customers with a net surplus of heat, like a data center, to supply the system. Initially without a connection to the backbone, the newest Mijnwater cluster under development will not be able to take advantage of this, so heat will need to be generated on site as long as the cluster is not balanced. The modular design of 5GDHC allows for this, regardless of the types of heat sources that are available at the cluster location. Currently in different EU demonstration projects, the implementation of low temperature industrial waste heat and sewage heat is realized (LIFE4heat, 2018; Heatnet NWE, 2016; REWARDHeat, 2019). As long as there is sufficient storage available, any heat source that can provide the total yearly amount of heat needed can be applied to balance the cluster.

Current methods of analysis used for planning district heating and cooling systems are based on one-year data of climatology, demand and supply or typical meteorological years. However, with further climate change and expected higher probabilities of extremes in terms of colds and heat waves, this may not prove to be a reliable basis of inputs for the system (Pyrgou et al., 2017). Methods for estimating fu- ture building energy consumption taking into account more extreme weather events have been proposed by, among others, Crawley (2008), Crawley and Lawrie (2015) and Hosseini et al. (2018). Combined with the higher required cooling load resulting from enhanced insulation grades in refurbished buildings and increasing urban heat island effects (Kolokotroni et al., 2012), a new ground for designing neighborhood energy profiles based on more extreme weather variations is appropriate.

While a top-down analysis of the exact size and composition of the system as proposed here may give an optimal technical solution, in reality a system is dependent on its users for implementation. Huijts et al. (2012) show that trust has a large impact on citizen acceptance of a technology and trust itself is influenced by procedural fairness. In the case of transitioning neighborhoods to new sources of heat, some citizens may not perceive the procedure of selecting the order and matter of the transition as fair, leading to citizens not accepting the optimal solution. Even if the procedure is fair, an optimal solution for the neighborhood might not always align with the optimal individual solution in the case of 5GDHC. Perceived distributive fairness may also influence citizen attitude (Huijts et al., 2012) and thus acceptance of 5GDHC technology. The final system design should take this into account, even if it does not lead to the highest overall technical efficiency.

\section{Conclusions}

5GDHC is a decentralized, bi-directional, close to ground temperature district heating and cooling concept that is based on the principle of closing energy loops as much as possible and using renewable sources to bridge the gap between supply and demand. The concept combines the principles of future urban heating and cooling systems proposed by Lund et al. (2014) with the principles of local energy grids engineered around individual sources. Lacking a return flow, consumption of heat is considered supply of cold and vice versa. 5GDHC systems provide a high level of flexibility as a result of their integration of heating, cooling and electricity infrastructures and the availability of storage facilities at different temperatures and time scales. By making smart use of this flexibility, the system is modular and can be extended with almost any type of consumer and renewable heat or cold source. This is a necessary feature in future urban energy systems, as high temperature renewable heat sources like solid biomass or waste incineration will not be able to cover the total heat demand in the European built environment (Persson, 2015). Optimizing 5GDHC systems is a non-trivial task, as the complexity and different temperature levels introduce a large number of degrees of freedom. A fitting methodology of optimizing both design and operation of a 5GDHC system is energy hub optimization, although existing models lack the capability of modeling floating temperature levels. We pro- 
pose that future work should focus on integrating 5GDHC characteristics in existing energy hub models.

The Mijnwater system in Heerlen, Netherlands is putting the 5GDHC principles into practice. The grid was originally a low temperature heat and cold supply grid using a shallow geothermal source and a linear approach to supply and demand. The system is now converted to a warm and cold pipe structure that facilitates prosumers, bi-directional flow and decentralized production of heat and cold. This shows that $5 \mathrm{GDHC}$ principles can be applied in large scale district heating and cooling systems.

Data availability. The article reviews the development of urban heating and cooling networks. It comes up with a clear definition of 5th generation heating and cooling systems and points out the research direction to investigate further optimization of such systems. No specific research data (measuring or monitoring data) have been used for this. All material necessary for constituting this review, definition and research outlook have been taken from the literature; all these sources are documented in the reference list.

Author contributions. Initial conceptualization of this work has been done by SB under supervision of WI and SCD. Extensive literature research on the topic has been carried out by SB. Figures 1 and 2 were created by SB with conceptual inputs from HE. The original draft has been written by SB under supervison of WI and SCD. Successive drafts have been reviewed, substantively supplemented and edited by WI, SCD and HE. Financial support for this work has been acquired by WI and SCD. SB had the lead in revising the article based on the first round of review comments. WI carried out the final revisions and the proofreading.

Competing interests. The authors declare that they have no conflict of interest.

Special issue statement. This article is part of the special issue "European Geosciences Union General Assembly 2019, EGU Division Energy, Resources \& Environment (ERE)". It is a result of the EGU General Assembly 2019, Vienna, Austria, 7-12 April 2019.

Financial support. This research has been supported by European Union's Interreg North-West Europe program (grant no. NWE795) and the Safety in Urban Environments research program of the Open University of the Netherlands.

Review statement. This paper was edited by Sonja Martens and reviewed by Sabine Jansen and one anonymous referee.

\section{References}

Buffa, S., Cozzini, M., D'Antoni, M., Baratieri, M., and Fedrizzi, R.: 5th generation district heating and cooling systems: A review of existing cases in Europe, Renewable and Sustainable Energy Reviews, 104, 504-522, https://doi.org/10.1016/j.rser.2018.12.059, 2019.

Bünning, F., Wetter, M., Fuchs, M., and Müller, D.: Bidirectional low temperature district energy systems with agent-based control: Performance comparison and operation optimization, Appl. Energ., 209, 502-515, https://doi.org/10.1016/j.apenergy.2017.10.072, 2018.

CE Delft: Towards a climate-neutral built environment in 2050, CE Delft, Delft, 2016.

CE Delft: Weg van gas: Kansen voor de nieuwe concepten Lage Temperatuur Aardwarmte en Mijnwater, Tech. rep., CE Delft, Delft, 2018.

Connolly, D., Lund, H., Mathiesen, B. V., Werner, S., Möller, B., Persson, U., Boermans, T., Trier, D., Østergaard, P. A., and Nielsen, S.: Heat roadmap Europe: Combining district heating with heat savings to decarbonise the EU energy system, Energ. Policy, 65, 475-489, https://doi.org/10.1016/j.enpol.2013.10.035, 2014.

Crawley, D. B.: Estimating the impacts of climate change and urbanization on building performance, J. Building Perform. Simu., 1, 91-115, https://doi.org/10.1080/19401490802182079, 2008.

Crawley, D. B. and Lawrie, L. K.: Rethinking the TMY: Is the "typical" meteorological year best for building performance simulation?, Proceedings of the 14th Conference of International Building Performance Simulation Association BS2015, 2655-2662, BSP Books, Hyderabad, India, 2015.

D2Grids: D2Grids - project summary, available at: http://www.nweurope.eu/projects/project-search/d2gridsincreasing-the-share-of-renewable-energy-by-acceleratingthe-roll-out-of-demand-driven-smart-grids-delivering-lowtemperature-heating-and-cooling-to-nwe-cities/, last access: 20 August 2019.

ECN: Nationale Energieverkenning 2017, Tech. rep., Energieonderzoek Centrum Nederland (ECN), Amsterdam/Petten, available at: https://publicaties.ecn.nl/ECN-O--17-018 (last access: 20 August 2019), 2017.

ETH Zürich: Die Energie von morgen, Abteilung Immobilien, ETH Zürich, Zürich, 2017.

European Commission: The Energy Performance of Buildings Directive, available at: https://eur-lex.europa.eu/legal-content/EN/ TXT/PDF/?uri=CELEX:32018L0844\&from=EN (last access: 20 August 2019), 2018.

EuroStat: Patterns of urban and city developments, in: Urban Europe - statistics on cities, towns and suburbs, chap. 3, 56-83, European Union, https://doi.org/10.2785/91120, 2016.

Geidl, M. and Andersson, G.: Optimal Power Flow of Multiple Energy Carriers, IEEE T. Power Syst., 22, 145-155, 2007.

Heatnet NWE: Project summary, available at: https://www.nweurope.eu/projects/project-search/heatnettransition-strategies-for-delivering-low-carbon-district-heat/ (last access: 20 August 2019), 2016.

Hoogervorst, N.: Toekomstbeeld Klimaatneutrale Warmtenetten in Nederland, Uitgeverij PBL, p. 80, available at: http://www.pbl.nl/publicaties/toekomstbeeld-klimaatneutrale- 
warmtenetten-in-nederland (last access: 20 August 2019), 2017.

Hosseini, M., Tardy, F., and Lee, B.: Cooling and heating energy performance of a building with a variety of roof designs; the effects of future weather data in a cold climate, J. Build. Eng., 17, 107-114, https://doi.org/10.1016/j.jobe.2018.02.001, 2018.

Huijts, N. M., Molin, E. J., and Steg, L.: Psychological factors influencing sustainable energy technology acceptance: A review-based comprehensive framework, Renewable and Sustainable Energy Reviews, 16, 525-531, https://doi.org/10.1016/j.rser.2011.08.018, 2012.

IPCC: IPCC special report on the impacts of global warming of $1.5^{\circ} \mathrm{C}$ : Summary for policy makers, Tech. Rep. October 2018, Intergovernmental Panel on Climate Change, available at: http: //www.ipcc.ch/report/sr15/ (last access: 20 August 2019), 2018.

Juwet, G. and Ryckewaert, M.: Energy transition in the nebular city: Connecting transition thinking, metabolism studies, and urban design, Sustainability (Switzerland), 10, 955, https://doi.org/10.3390/su10040955, 2018.

Kolokotroni, M., Ren, X., Davies, M., and Mavrogianni, A.: London's urban heat island: Impact on current and future energy consumption in office buildings, Energ. Buildings, 47, 302-311, https://doi.org/10.1016/j.enbuild.2011.12.019, 2012.

LIFE4heat: LIFE4HeatRecovery project, available at: http://www. life4heatrecovery.eu/en/Project (last access: 20 August 2019), 2018.

Lund, H., Werner, S., Wiltshire, R., Svendsen, S., Thorsen, J. E., Hvelplund, F., and Mathiesen, B. V.: 4th Generation District Heating (4GDH). Integrating smart thermal grids into future sustainable energy systems, Energy, 68, 1-11, https://doi.org/10.1016/j.energy.2014.02.089, 2014.

Mancarella, P.: MES (multi-energy systems): An overview of concepts and evaluation models, Energy, 65, 1-17, https://doi.org/10.1016/j.energy.2013.10.041, 2014.

Mesquita, L., McClenahan, D., Thornton, J., Carriere, J., and Wong, B.: Drake Landing Solar Community: 10 Years of Operation, in: ISES Conference Proceedings, 1-12, https://doi.org/10.18086/swc.2017.06.09, 2017.

Mohammadi, M., Noorollahi, Y., Mohammadi-ivatloo, B., and Yousefi, H.: Energy hub: From a model to a concept - A review, Renewable and Sustainable Energy Reviews, 80, 15121527, https://doi.org/10.1016/j.rser.2017.07.030, 2017.

Nijpels, E.: Ontwerp Klimaatakkoord, available at: https://www.klimaatakkoord.nl/binaries/klimaatakkoord/ documenten/publicaties/2018/12/21/ontwerp-klimaatakkoord/ OntwerpvanhetKlimaatakkoord_compleet_web.pdf (last access: 20 August 2019), 2018.

Orehounig, K., Evins, R., Dorer, V., and Carmeliet, J.: Assessment of renewable energy integration for a village using the energy hub concept, Enrgy. Proced., 57, 940-949, https://doi.org/10.1016/j.egypro.2014.10.076, 2014.

PALET 3.0: Parkstad Limburg Energietransitie, Tech. rep., Stadsregio Parkstad Limburg, Heerlen, 2016.

Pellegrini, M. and Bianchini, A.: The innovative concept of cold district heating networks: A literature review, Energies, 11, 236, https://doi.org/10.3390/en11010236, 2018.
Persson, U.: District heating in future Europe: Modelling expansion potentials and mapping heat synergy regions, Phd thesis, Chalmers University of Technology, Göteborg, Sweden, 2015.

Planbureau voor de Leefomgeving: Toekomstbeeld Klimaatneutrale Warmtenetten in Nederland, Uitgeverij PBL, p. 80, available at: http://www.pbl.nl/publicaties/ toekomstbeeld-klimaatneutrale-warmtenetten-in-nederland (last access: 20 August 2019), 2017.

Pyrgou, A., Castaldo, V. L., Pisello, A. L., Cotana, F., and Santamouris, M.: Differentiating responses of weather files and local climate change to explain variations in building thermalenergy performance simulations, Solar Energy, 153, 224-237, https://doi.org/10.1016/j.solener.2017.05.040, 2017.

REWARDHeat: Renewable and Waste Heat Recovery for Competitive District Heating and Cooling Networks, available at: https://cordis.europa.eu/project/rcn/224317/factsheet/en, last access: 20 August 2019.

Sanner, B., Ria, K., Land, A., Mutka, K., Papillon, P., Stryi-Hipp, G., Weiss, W., Bakker, M., Froning, S., Landolina, S., Howak, T., and Sparber, W.: Common Vision for the Renewable Heating \& Cooling sector in Europe, Tech. Rep. January, RHC Platform, Brussels, https://doi.org/10.2788/20474, 2011.

Truong, N. L. and Gustavsson, L.: Cost and primary energy efficiency of small-scale district heating systems, Appl. Energ., 130, 419-427, https://doi.org/10.1016/j.apenergy.2014.05.031, 2014.

UNFCCC: The Paris Agreement, available at: https://unfccc.int/ process-and-meetings/the-paris-agreement/the-paris-agreement (last access: 20 August 2019), 2018.

Verhoeven, R., Willems, E., Harcouët-Menou, V., De Boever, E., Hiddes, L., Veld, P. O. T., and Demollin, E.: Minewater 2.0 project in Heerlen the Netherlands: Transformation of a geothermal mine water pilot project into a full scale hybrid sustainable energy infrastructure for heating and cooling, Enrgy. Proced., 46, 58-67, https://doi.org/10.1016/j.egypro.2014.01.158, 2014.

Walker, S., Corten, K., Labeodan, T., Maassen, W., and Zeiler, W.: A load profile study of different buildings to identify neighborhood energy flexibility with exchange possibilities, Enrgy. Proced., 122, 553-558, https://doi.org/10.1016/j.egypro.2017.07.411, 2017.

Werner, S.: International review of district heating and cooling, Energy, 137, 617-631, https://doi.org/10.1016/j.energy.2017.04.045, 2017.

Wiebes, E.: Kamerbrief over gaswinning Groningen, available at: https://www.rijksoverheid.nl/ binaries/rijksoverheid/documenten/kamerstukken/ 2018/03/29/kamerbrief-over-gaswinning-groningen/ kamerbrief-over-gaswinning-groningen.pdf (last access: 20 August 2019), 2018.

Winkel, T., de Visser, E., and Lensink, S.: Invulling van $16 \%$ hernieuwbare energie in 2020, Tech. rep., ECN, Ecofys, Utrecht, the Netherlands, 2013. 